\title{
Missing Petrodollars: Middle East and
}

\section{Africa}

\author{
Akash Malhotra \\ Center for Economic Studies and Planning, Jawaharlal Nehru University, New Delhi, India \\ JEL classification: E01, F02, F32, F38
}

Keywords:

Offshore wealth, MENA, Saudi Arabia, Iraq, Nigeria.

\section{Abstract}

Over the last two decades, offshore banking and accumulation of real foreign assets by residents of the oil-rich Middle East and North Africa (MENA) region has come under increased scrutiny by the media, financial watchdogs and anti-terrorism authorities. By taking the case of three net exporters from MENA, viz., Saudi Arabia, Iraq and Nigeria, this article attempts to estimate the magnitude of offshore wealth which is 'missing' from the official financial records of these nations. The methodology employed here makes use of Net Errors and Omissions reported in the Balance of Payment (BoP) statement to estimate annual unrecorded capital flight. As per our benchmark estimates, the hidden or missing offshore wealth has been on a persistent rise in the last decade for the three MENA nations under study, with Iraq witnessing the highest rate of accumulation of hidden offshore wealth (as a proportion of national income). These countries have been running large trade surpluses but their accumulation of foreign assets as reported in their official statistics have been relatively modest. In absolute numbers, the estimate of missing offshore wealth stands at USD 420 billion for Saudi Arabia, and conservative estimates of hidden foreign wealth for Nigeria and Iraq are USD 163 billion and USD 146 billion respectively. 


\section{Introduction}

The IMF staff estimated in 1996 that the amount of money laundered across the globe in a year is around 2 - 5\% of global GDP (Quirk, 1996). According to an estimate by UNODC, criminals, excluding tax evaders, laundered around USD 1.6 trillion, which amounts to 2.7 percent of world GDP, in 2009 alone (Pietschmann and Walker, 2011). A 2016 survey by PwC, ascribed a similar figure to global money laundering transactions of roughly $\$ 1$ trillion to $\$ 2$ trillion annually, accounting for about 2\% to 5\% of global GDP (PwC, 2016).

When it comes to identifying illicit offshore transactions, the Middle East region poses special challenges owing to an unusually wide array of both multinational banks and local banks with an international presence. The presence of global trading hubs, combined with a very high level of cash transactions and money service businesses, and a geographical proximity to politically unstable or sanctioned regimes further aggravates the situation. The money is laundered out of these MENA countries for numerous reasons, viz. trafficking and criminal activities, to finance terrorist groups in rival countries, or by corrupt rich residents to acquire assets in relatively stable OECD countries which they do not want to declare in their home country for various reasons. C4ADS (2018) highlights how drug traffickers, funders of armed groups such as Hezbollah, and even a cousin of Syrian despot Bashar al-Assad, use real estate assets in Dubai to launder money.

In this article, we focus on three oil-rich MENA countries: Saudi Arabia, Iraq and Nigeria. To get an estimate of the accumulation of offshore wealth by residents of a country, the obvious starting point is the analysis of that country's trade balance and balance of payments. While doing such an analysis, a striking fact emerges which is common to all the three economies under study - these economies have been running large trade surpluses but their accumulation of foreign assets as reported in their official statistics have been relatively modest.

For instance, in 2012 Saudi Arabia reported a current account surplus of \$164 billion and a capital account balance of $\$ 0 \mathrm{bn}$, and yet it recorded a foreign account surplus of only $\$ 122$ billion instead of $\$ 164$ billion. This requires about $\$ 42$ billion to be ascribed to net errors and omissions to balance the accounts in BoP statement. Such huge errors arise either from under-estimation of Saudi investment flows abroad, or over-estimation of foreign investment 
inflows. A similar trend emerges for Iraq and Nigeria as well. All these MENA nations have poor Fragile State Index (FSI) scores as reported by Messner (2018), with Saudi Arabia having an "Elevated Warning" status, and Nigeria and Iraq on "Alert" and "High Alert" status respectively. Given the natural inclination of residents of these countries to move their wealth to stable countries and the weaknesses of legal and statistical system in these three MENA nations, consistently negative net errors and omissions in their BoP statistics might serve as a useful indicator of the unrecorded capital flight taking place each year.

Over the period of 2009 to 2016, Saudi Arabia, on average, ran a current account surplus of $13 \%$ of its national income each year and reported accumulation of foreign wealth close to $55 \%$ of its national income. In contrast, another oil-rich but developed country like Norway, with comparable current account surpluses (about 10\% of its national income each year) gathered much larger wealth in foreign assets, more than $135 \%$ of its current national income, over the same period. A striking difference between the BoP statistics of these two countries is their Net Errors and Omissions. While the net errors and omissions in Norwegian BoP fluctuate randomly around zero, the Saudi errors are consistently negative when not zero (see Fig. 1). The randomness in Norwegian error data shares resemblance with actual statistical errors and flukes in BoP data, whereas the Saudi errors hint more towards a systematic underreporting of investment flows abroad.

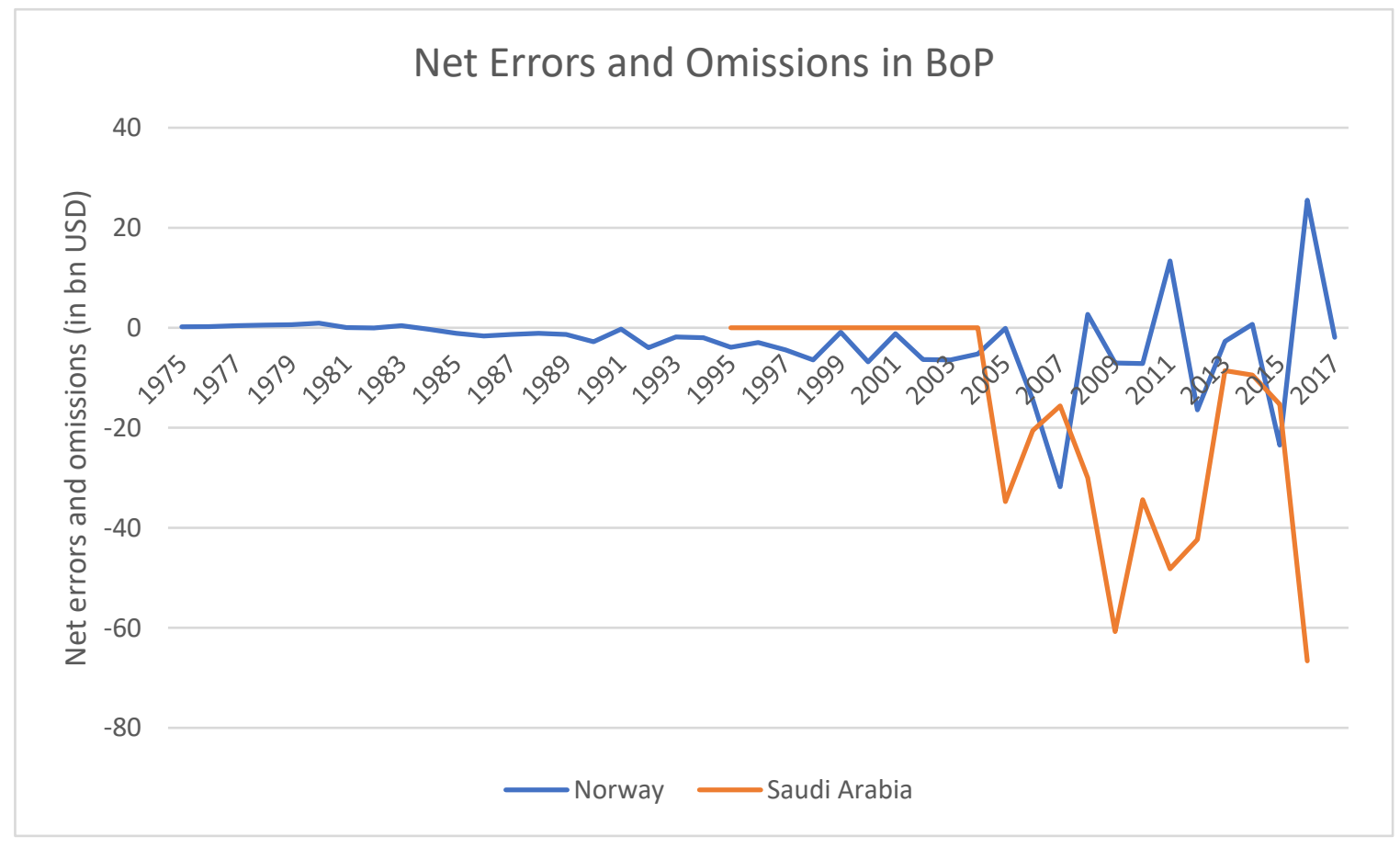

Figure 1. Net Errors and Omissions in BoP statistics: Norway and Saudi Arabia 
The evolution of the net errors and omissions over time is going to form the crux of the methodology employed for estimating hidden offshore wealth in this article. The rest of the article is organized as follows: Section 2 explains the methodology and data sources. Section 3 presents the estimates of hidden offshore wealth and analyses the limitations of the employed methodology and reliability of estimates obtained thereof in the context of each country. Section 5 concludes with a couple of recommendations for countering money laundering.

\section{Data and Methodology}

The data series on Balance of Payment (BoP) and International Investment Position for all nations were sourced from International Financial Statistics database of IMF. Data on country GDP, National Income ${ }^{1}$ and GDP growth rate were sourced from The World Bank database. World and OECD GDP annual growth rates were also sourced from The World Bank database. All data series are in current US dollars.

Net errors and omissions

$$
=\text { Net financial account }-(\text { Current }+ \text { Capital account balance })
$$

The above equation is an identity for external sector. As per BPM6 of IMF (2013), net errors and omissions reflect a residual category required to ensure that accounts in the BoP statement sum to zero. Current account balance is the sum of net exports of goods and services and net primary and secondary income. Net capital account records capital transfers, including government debt forgiveness, as well as acquisitions and disposals of non-produced non-financial assets, such as sales of leases and licenses, land acquired by embassies etc. The usage of the terms capital and financial accounts in this article are consistent with the UN System of National Accounts (SNA, 2008), which differentiates between financial and capital transactions. The net financial account records net acquisition and disposal of financial assets and liabilities. It is an indicator of how net lending to or borrowing from non-residents is financed.

\footnotetext{
${ }^{1}$ National Income used in this study is World Bank staff estimates of adjusted net national income, which is obtained after subtracting consumption of fixed capital and depletion of natural resources from Gross National Income (GNI), based on sources and methods described in Lange et al. (2018).
} 
The international investment position serves as the measure of official foreign wealth owned by each country. Motivated by Novokmet et al. (2018), we estimate annual capital flight with net errors and omissions. We then obtain our estimates of missing offshore wealth by cumulating the yearly capital flight while compounding with appropriate rates of return on this hidden offshore wealth. In our benchmark scenario, cumulated hidden offshore wealth is assumed to earn an annual rate of return equal to the GDP growth rate ' $g$ ' of OECD. This assumption derives its credibility from the fact that the primary money laundering hubs of the financial world are located in OECD countries, namely - Estonia, Latvia, Ireland, Switzerland and the money laundering capital of the world: London (UK). Moreover, money launderers are expected to park their illicit money in politically stable and rich OECD countries such as UK or Switzerland than a relatively volatile emerging economy. In our lower bound scenario, we account for the faster consumption of hidden offshore wealth and assume hidden wealth to grow at rate $\mathrm{g}-2 \%$. In our upper bound scenario, we assume that offshore hidden wealth earns a return at rate $g+2 \%$. Even after accounting for appropriate rates of return earned by hidden offshore wealth, the proposed methodology provides, at best, a conservative or lower estimate of hidden offshore wealth owing to the following four tacit assumptions:

\section{Consistent negative errors and omissions}

The country's BoP should record consistent negative errors and omissions to give reliable estimates of the illicit cross-border capital flight taking place through exports misinvoicing, smurfing, layering, mirror trades and other fictitious transactions.

2. Order of capital flight should be greater than statistical errors

In reality, net errors and omissions reported in BoP would contain both, laundered money as well genuine statistical errors and flukes. The proposed methodology would give a reliable estimate of hidden wealth only if the genuine statistical errors are negligible as compared to the capital flight out of the country. The significance of this assumption is accentuated in a hypothetical scenario wherein actual statistical errors are positive in sign and of the same order as laundered money (negative in sign), thus cancelling each other and resulting in close to zero net errors and omissions, rendering our methodology inefficacious. 


\section{Consistent exporter of illicit money}

The nation of interest should behave consistently as an exporter of laundered money and should not switch roles with havens during the period of analysis; otherwise, the exercise of measuring annual capital flight by net errors and omissions becomes untenable.

4. Initial value

To begin cumulating the net errors and omissions, we have to choose a starting year (which depends on the availability of data) and make an assumption about the magnitude of hidden offshore wealth already in existence. In our methodology, we implicitly assume that existing hidden offshore wealth at the time when BoP data series begins is negligible or close to zero. Consequently, our methodology gives reliable estimates only for nations which historically didn't suffer from significant illicit capital flights and then abruptly began experiencing huge capital flights somewhere in the middle of the analysis period. Otherwise, the proposed methodology will severely underestimate the accumulated hidden offshore wealth owing to the compounding effects of existing wealth.

Notice that assumption 2 and 3 are maintained (unverifiable with BoP data) assumptions. The limitations of the proposed methodology and consequences arising out of those limitations will be discussed in a contextual sense while analysing country-specific data in Section 3. Having identified the shortcomings of this methodology, now, it is important to turn attention to the simplicity by which this methodology produces remarkably reliable estimates of hidden offshore wealth, at least in terms of order of magnitude, when the aforementioned assumptions obtain as demonstrated for Russia by Novokmet et al. (2018) and for Saudi Arabia in Section 3.1 of the present article.

\section{Results and Analysis}

As per our benchmark estimates, the hidden or missing offshore wealth has been on a persistent rise in the last decade for at least three MENA countries, viz., Saudi Arabia, Nigeria and Iraq (see Fig. 2); the same was found for Russia by Novokmet et al. (2018). As of 2016, the estimate of missing offshore wealth stands at USD 420 billion for Saudi Arabia, and 
conservative estimates of hidden foreign wealth for Nigeria ${ }^{2}$ and Iraq ${ }^{3}$ are USD 163 billion and USD 146 billion respectively. A clearer picture emerges if we look the missing offshore wealth as a proportion of current National Income of these countries (see Fig. 3), which accentuates the relatively larger problem of capital flight from war-torn Iraq during the last decade, resulting in a conservative estimate of hidden offshore wealth more than current national income of the country in 2016.

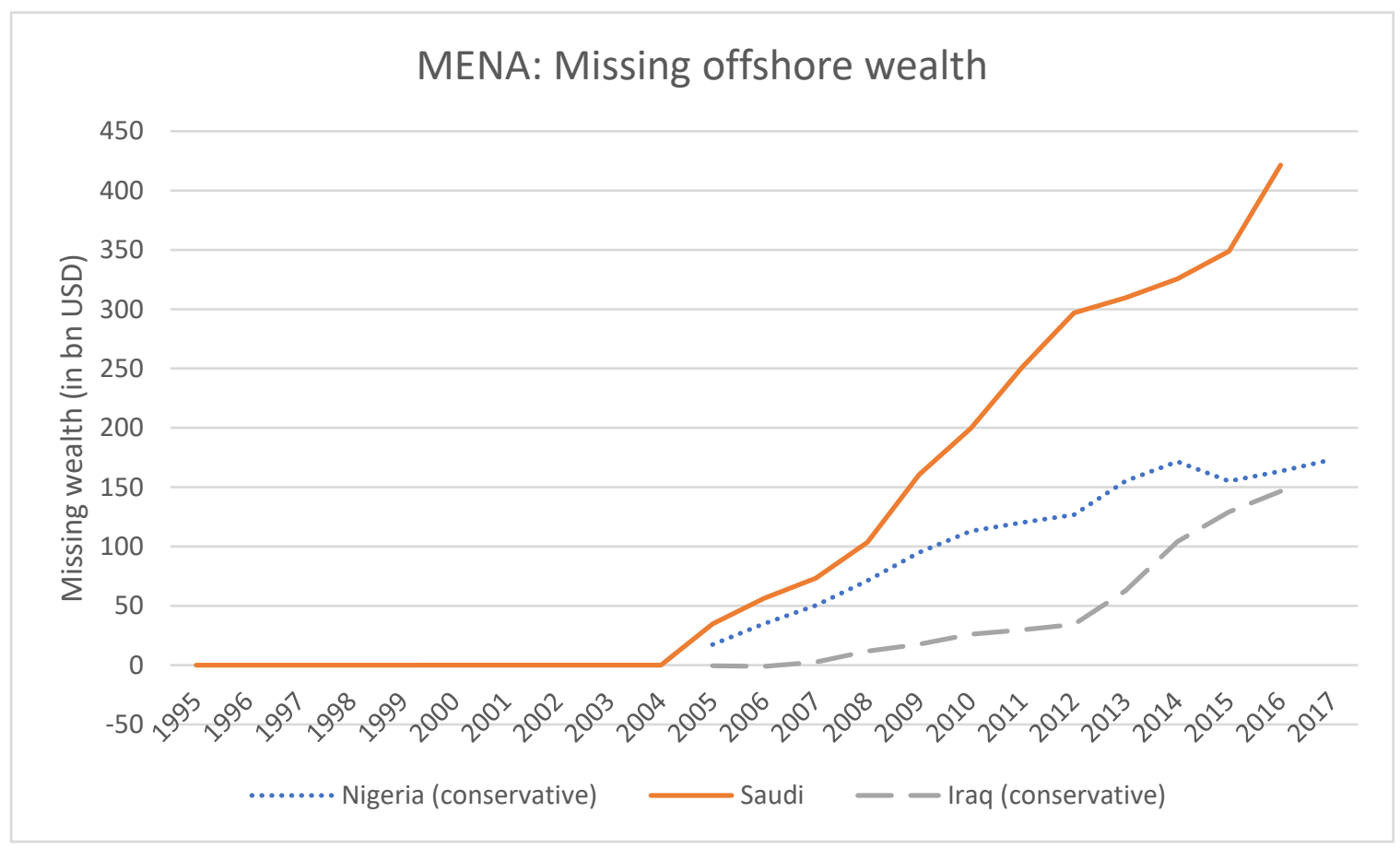

Figure 2. Benchmark estimates of missing offshore wealth

\footnotetext{
${ }^{2}$ For reasons discussed in Section 3.3, the net errors and omissions serve as reliable estimate of illicit capital flight from Nigeria only after 2004. Consequently, the hidden wealth reported in Fig. 2 represents only the wealth accumulated after 2005; hence, a conservative estimate.

${ }^{3}$ In the case of Iraq, we might be severely underestimating the magnitude of hidden foreign wealth as BoP data during Saddam regime is not available; the consequences of which are discussed in Section 3.2.
} 


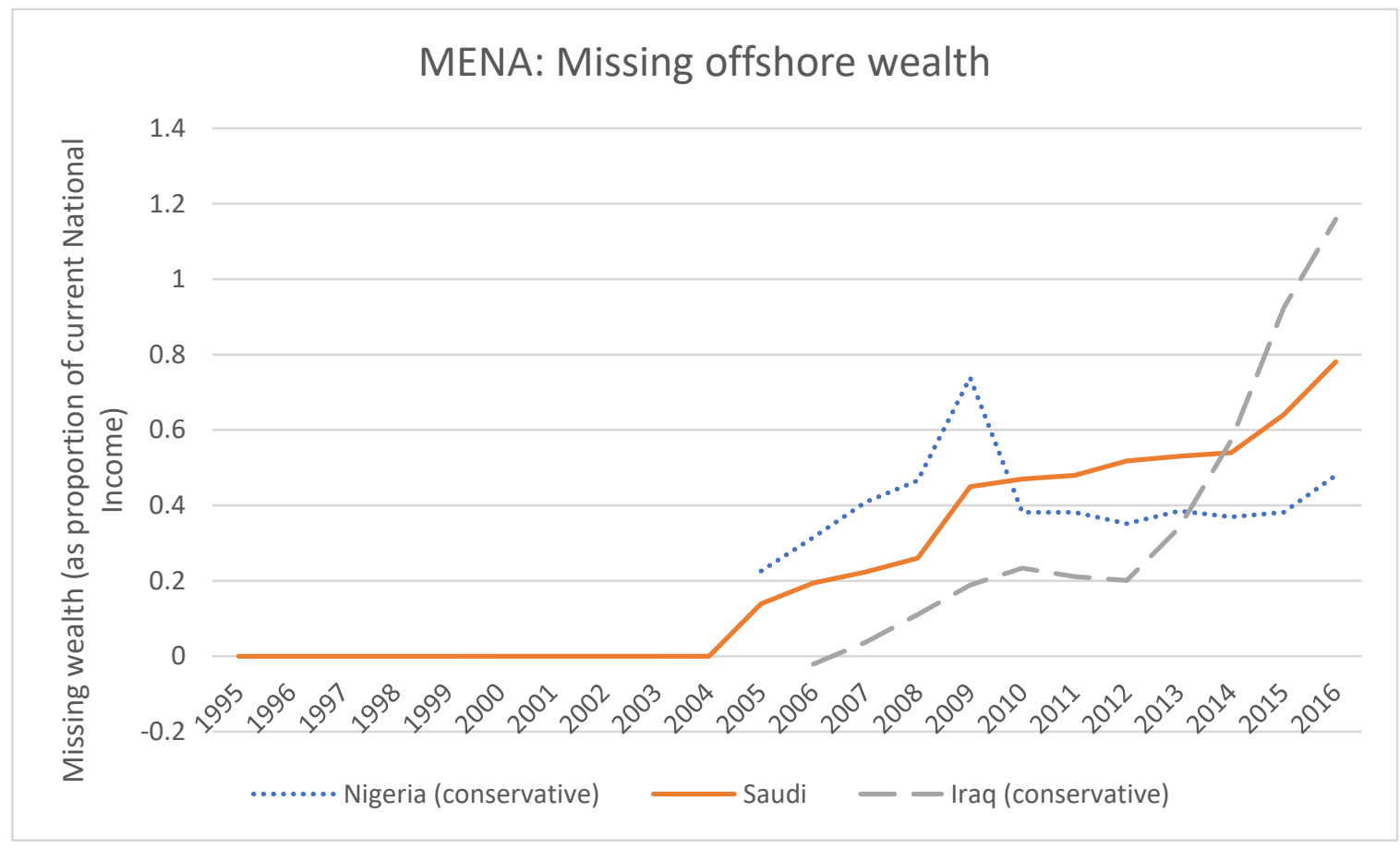

Figure 3. Missing offshore wealth (as proportion of current National Income)

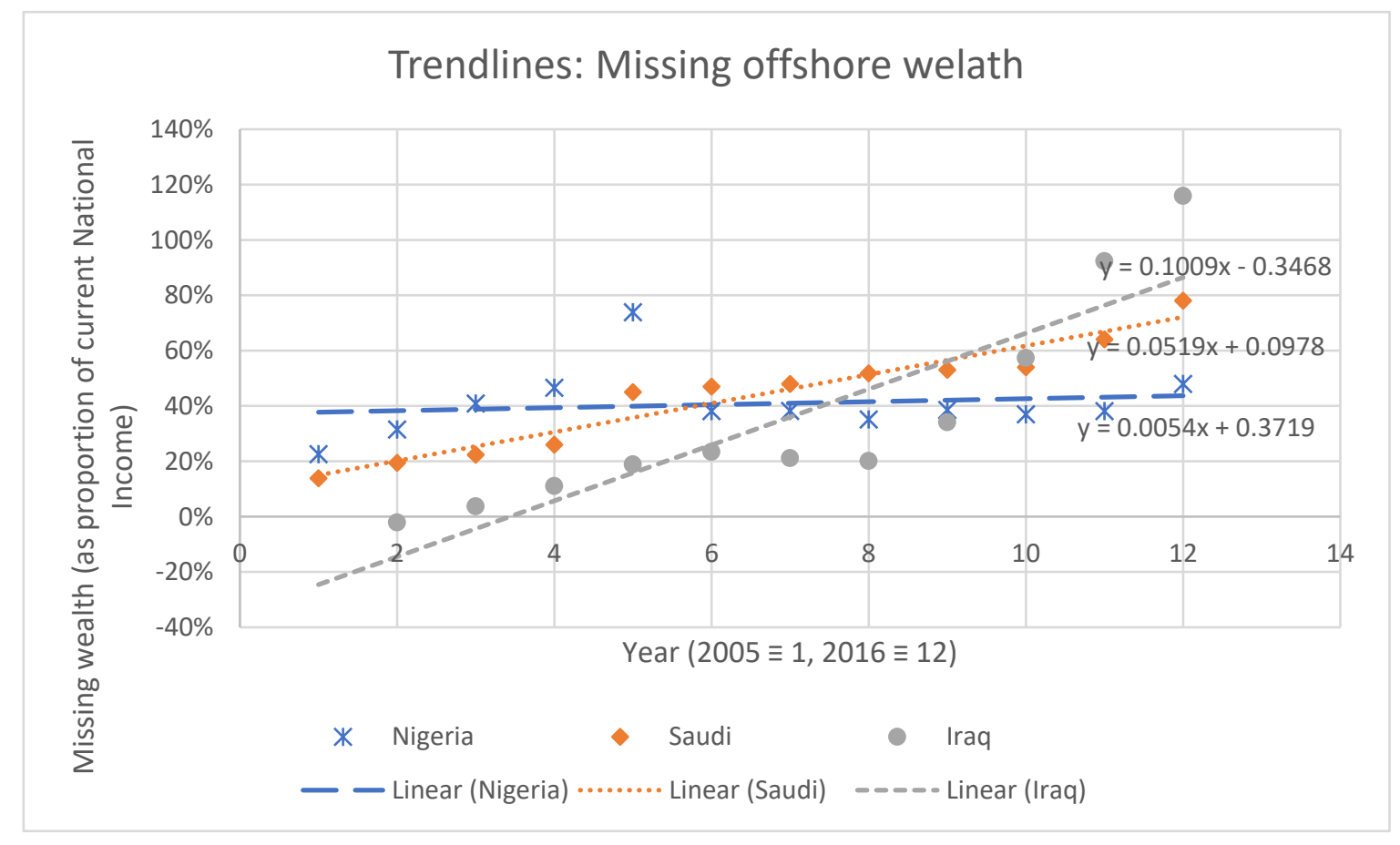

Figure 4. Trendlines for missing offshore wealth

Over the period of 2005-16, Iraq witnessed the highest rate of accumulation of hidden offshore wealth (as a proportion of national income), on average, as apparent from the largest positive slope of trendline in Fig. 4, followed by Saudi Arabia. However, if we look at the 
hidden offshore wealth as a proportion of total foreign wealth (= hidden + official $\left.{ }^{4}\right)$, then we observe that Nigeria has the highest proportion of foreign wealth hidden from official statistical records (see Fig. 5).

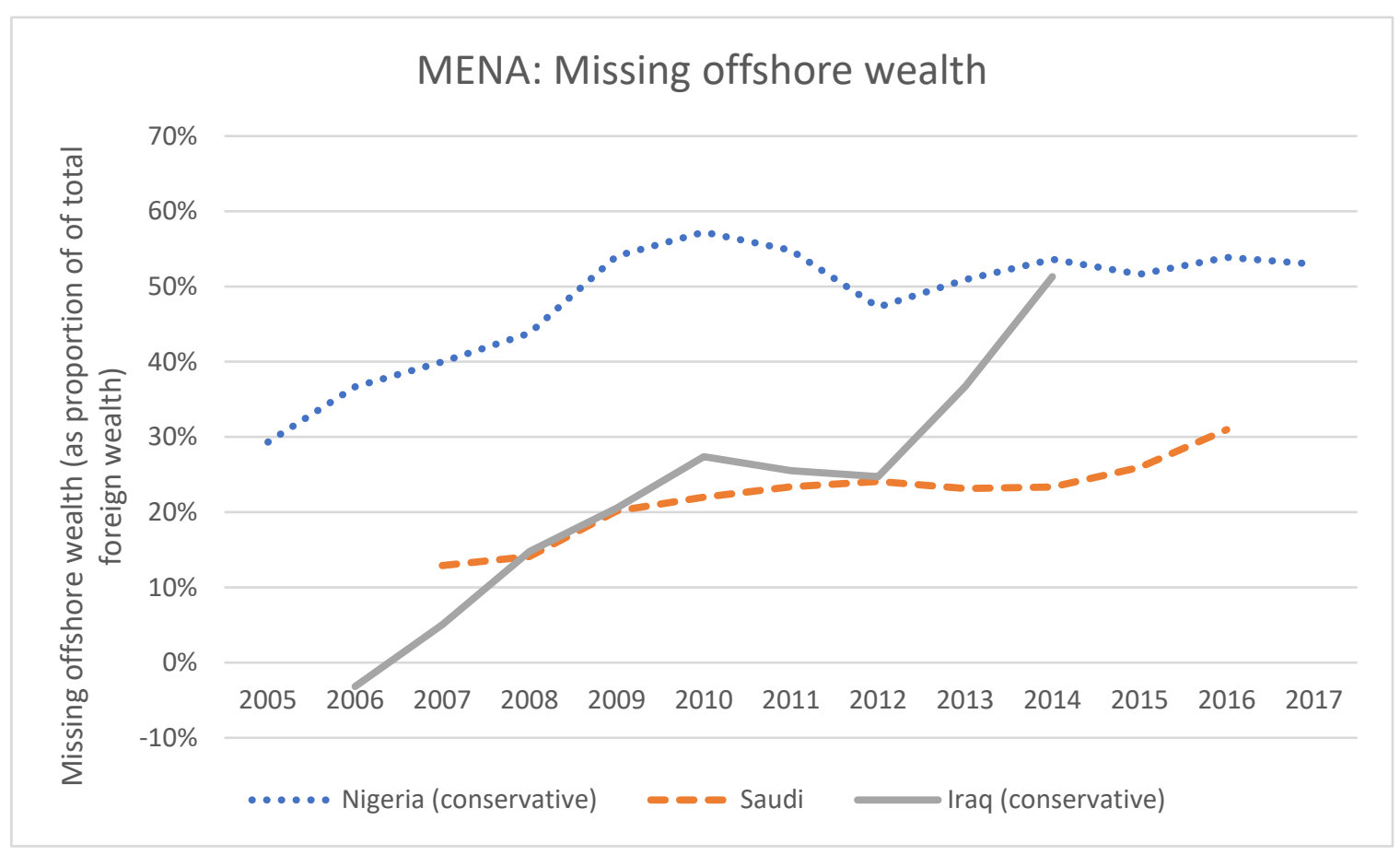

Figure 5. Missing offshore wealth (as proportion of total foreign wealth)

Now let's look at the evolution of hidden offshore wealth in these three MENA nations, individually.

\subsection{Saudi Arabia}

Over the 2007-16 period, the average annual current account surplus for Saudi Arabia was more than $15 \%$ of current national income. In other words, for every year in the last decade, Saudi Arabia was exporting about $15 \%$ of its annual output in excess to what it was importing. If we simply cumulate the current account surpluses over the 2007-2016 period (neglecting compounding effects), we get a figure close to $160 \%$ of national income. The paradoxical observation here is that during the same period its official foreign wealth grew only to about $170 \%$ of national income in 2016 from about $150 \%$ of national income in 2007.

\footnotetext{
${ }^{4}$ Official estimate of foreign wealth is appraised as net international investment position of a country, as reported in International Financial Statistics of IMF.
} 
The obvious explanation is illicit capital flight, i.e., some Saudi Arabian individuals and/or some Saudi corporations or government officials acting on behalf of these individuals were able to convert some of these trade surpluses into hidden offshore assets - foreign assets resulting from transactions that do not get properly recorded in Saudi official BoP statistics. A rough estimate of cumulated capital flight from Saudi Arabia in last decade is of the order of $140 \%$ of national income (given the fact that official foreign wealth increased by only $20 \%$ of national income). This claim of illicit capital flight from Saudi Arabia is further corroborated by a sudden jump in Net Errors and Omissions in its BoP statistics post-2005 (see Fig. 6).

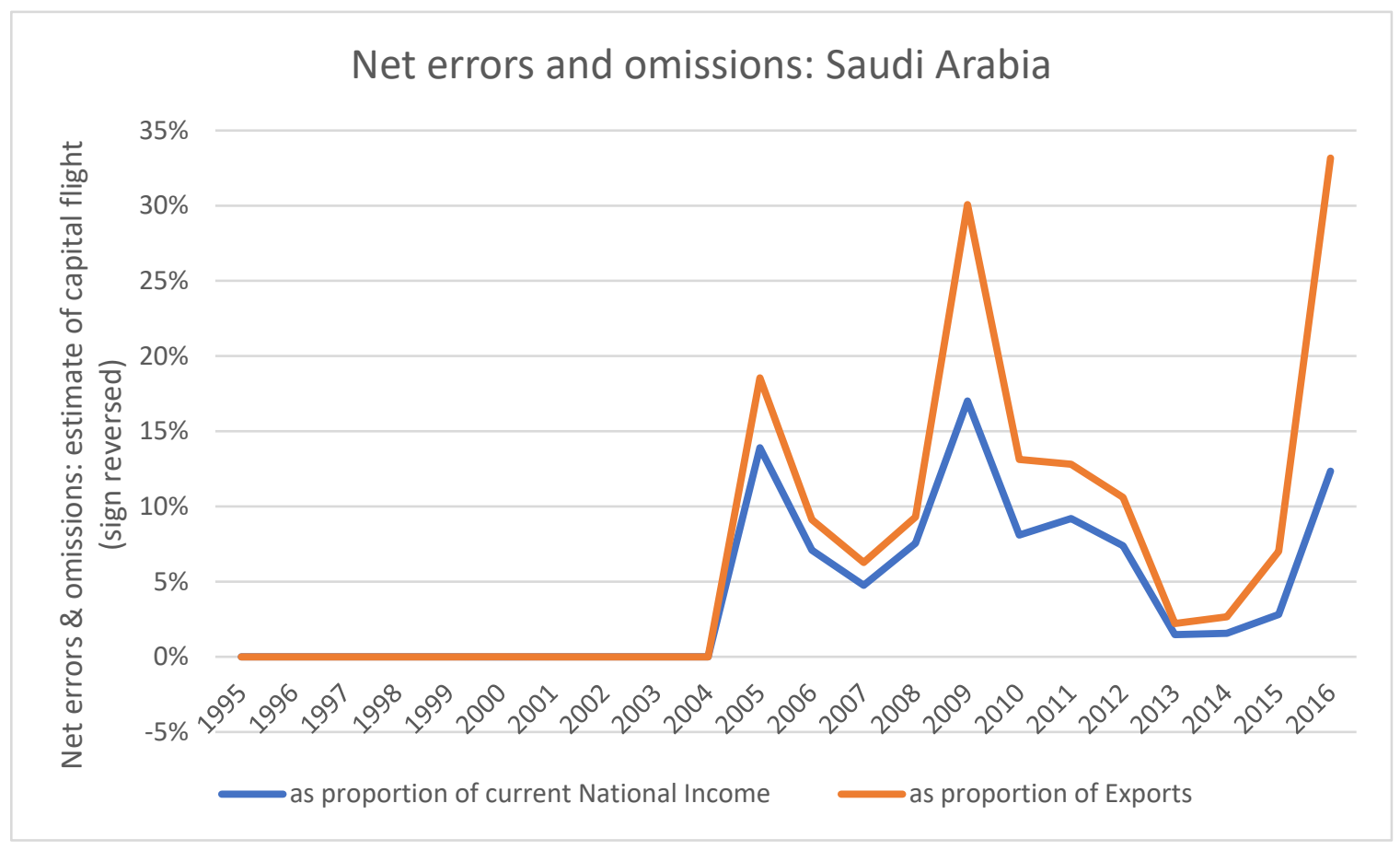

Figure 6. Net Errors and Omissions in BoP: Saudi Arabia

Notice that for Saudi Arabia, Net Errors and Omissions serve as a reliable indicator of annual capital flight as both the verifiable assumptions of our methodology, viz., consistent negative errors and zero initial value, are being met. As evident from Fig. 6, net errors and omissions reported in Saudi BoP statistics were close to zero from 1995 to 2004, then became suddenly significantly different from zero, and remained consistently negative (sign reversed in Fig. 6) for the rest of the period. This implies that capital flight in the period 1995-2004 was insignificant and significant illicit capital flight from Saudi Arabia, as measured by net errors and omissions, started only after 2004 allowing us to ascribe a zero value to hidden offshore 
wealth existing prior to 1995 . Consequently, the employed methodology would provide a reliable estimate of hidden offshore wealth for Saudi Arabia.

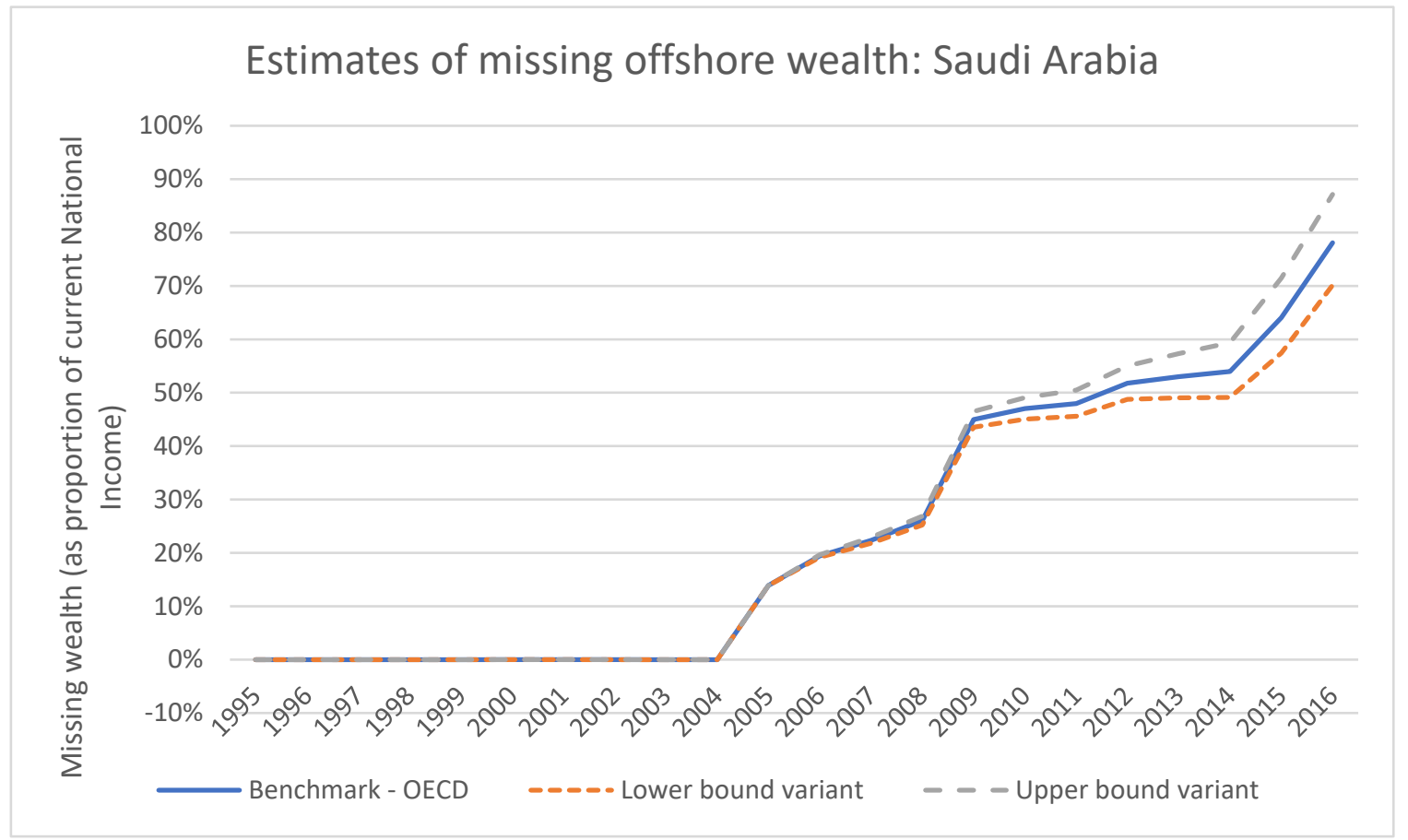

Figure 7. Missing wealth: Lower and Upper bounds

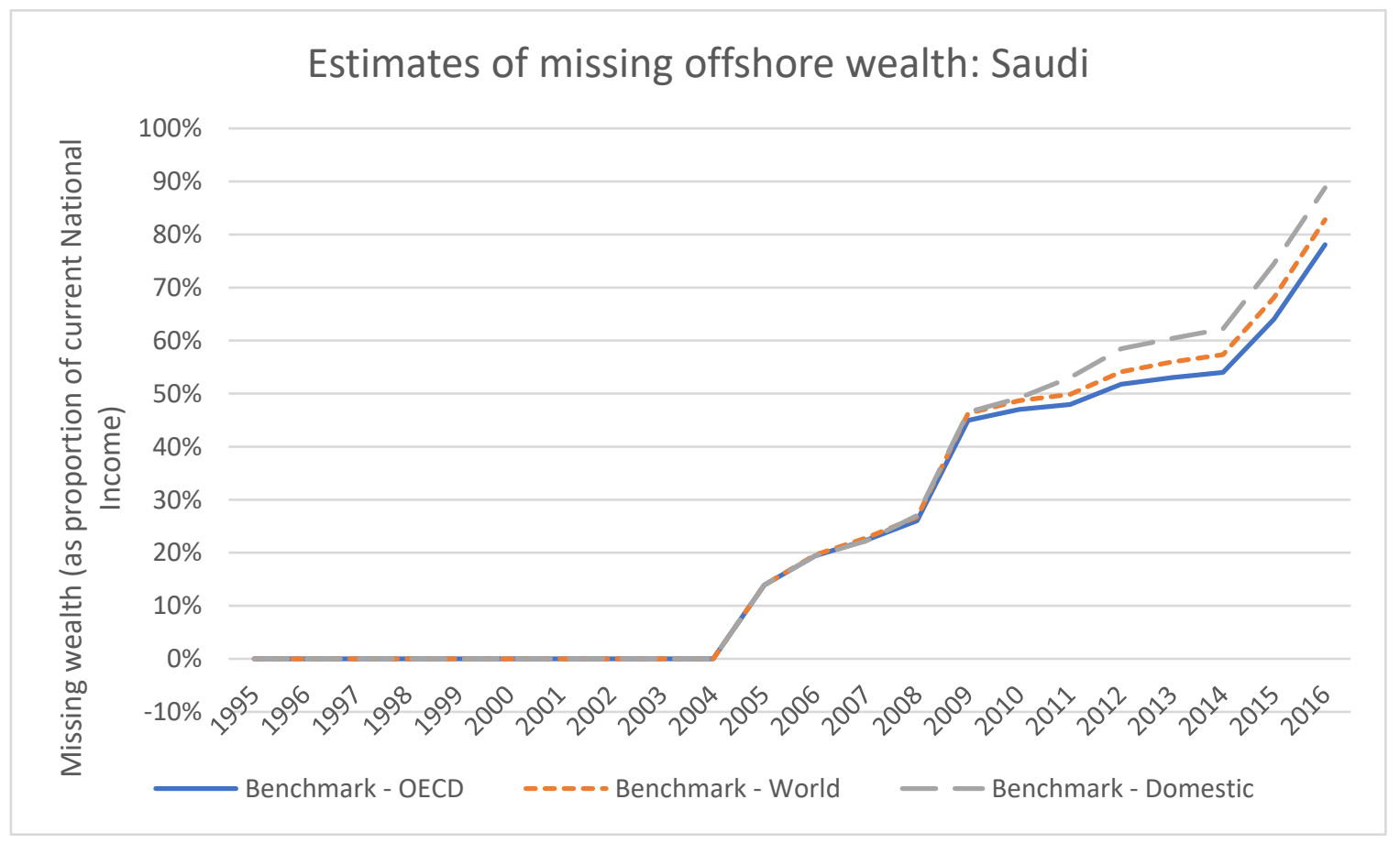

Figure 8. Missing wealth: varying growth rates

As per our benchmark estimate derived from OECD growth rate, the stock of Saudi wealth hidden in offshore assets stand at $78 \%$ of national income in 2016; having lower and upper 
bound at $70 \%$ and $87 \%$ respectively (see Fig. 7). As evident from Fig. 8 , if the benchmark rate of return on offshore wealth is taken as the world GDP growth rate or Saudi GDP growth rate, then the estimate of hidden offshore wealth comes out to be larger ( $83 \%$ or $89 \%$ respectively) than the OECD case (78\%). Apart from the desirability of OECD assets as described in Section 2 , taking lower OECD growth rate as the benchmark rate of return earned by hidden offshore wealth is also consistent with the fact the hidden wealth generally earns smaller returns than declared wealth due to transaction and administrative costs incurred in keeping that wealth hidden.

\subsection{Iraq}

A similar picture emerges for Iraq as well. Over the period of 2006 to 2014, Iraq, on an average, ran a current account surplus of $13 \%$ of national income per year which cumulates to around USD 154 billion, while the official wealth in the same period increased by only USD 64 billion (from $\$ 33 \mathrm{bn}$ to $\$ 98 \mathrm{bn}$ ). This discrepancy points towards a cumulated illicit capital flight of around $\$ 90$ bn in this eight-year period.

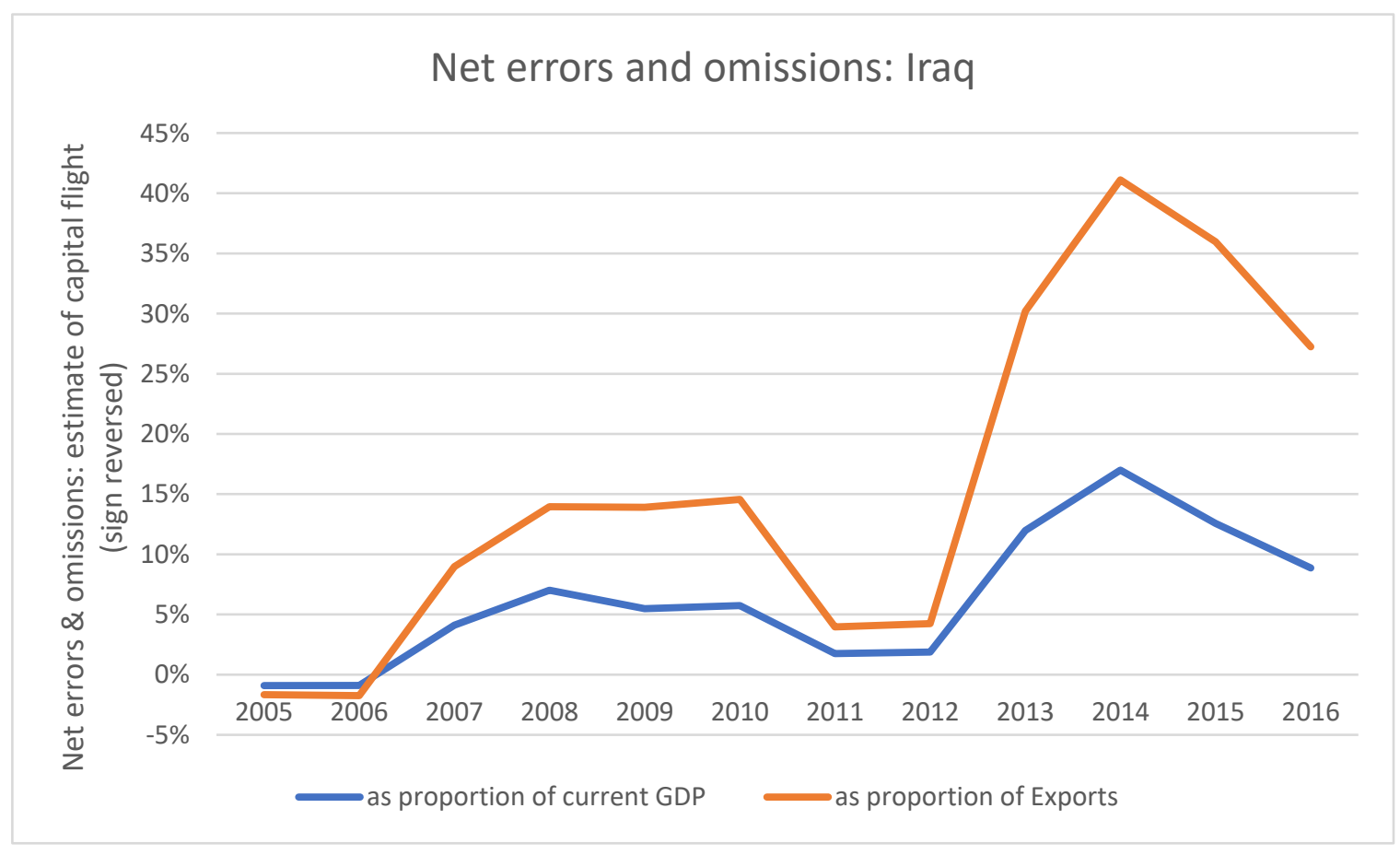

Figure 9. Net Errors and Omissions in BoP: Iraq

BoP data for Iraq is available only from 2005 whereas the data for net foreign investment position is available for the period of 2006 to 2014. The net errors and omissions, while remaining consistently negative (sign reversed in Fig. 9), has risen significantly from 2005 to 
2016. However, due to the lack of data prior to 2005 , we are not in the position to verify assumption 4 of initial zero value. Additionally, it's pretty hard to believe that illicit capital must not be flowing out of Iraq during the Saddam regime which witnessed political upheavals from the very beginning - Iraq-Iran war of 1980s, Gulf war of early 1990s, Operation Desert Fox of late 1990s and finally, the ousting of Saddam in 2003. Hence, it would be prudent to not ascribe zero value to the existing hidden offshore wealth in 2005. Interestingly, on simply cumulating the annual unrecorded capital flight (as measured by net errors and omissions) over the period $2006-14$, we obtain a figure close to $\$ 100$ bn which is in the vicinity of $\$ 90$ bn figure estimated earlier from the difference between cumulated current account surplus and change in official foreign wealth over this period. This provides support to the plausibility of assumption 2 by indicating that genuine statistical errors make a smaller part of the Net errors and omissions in Iraqi BoP statistics.

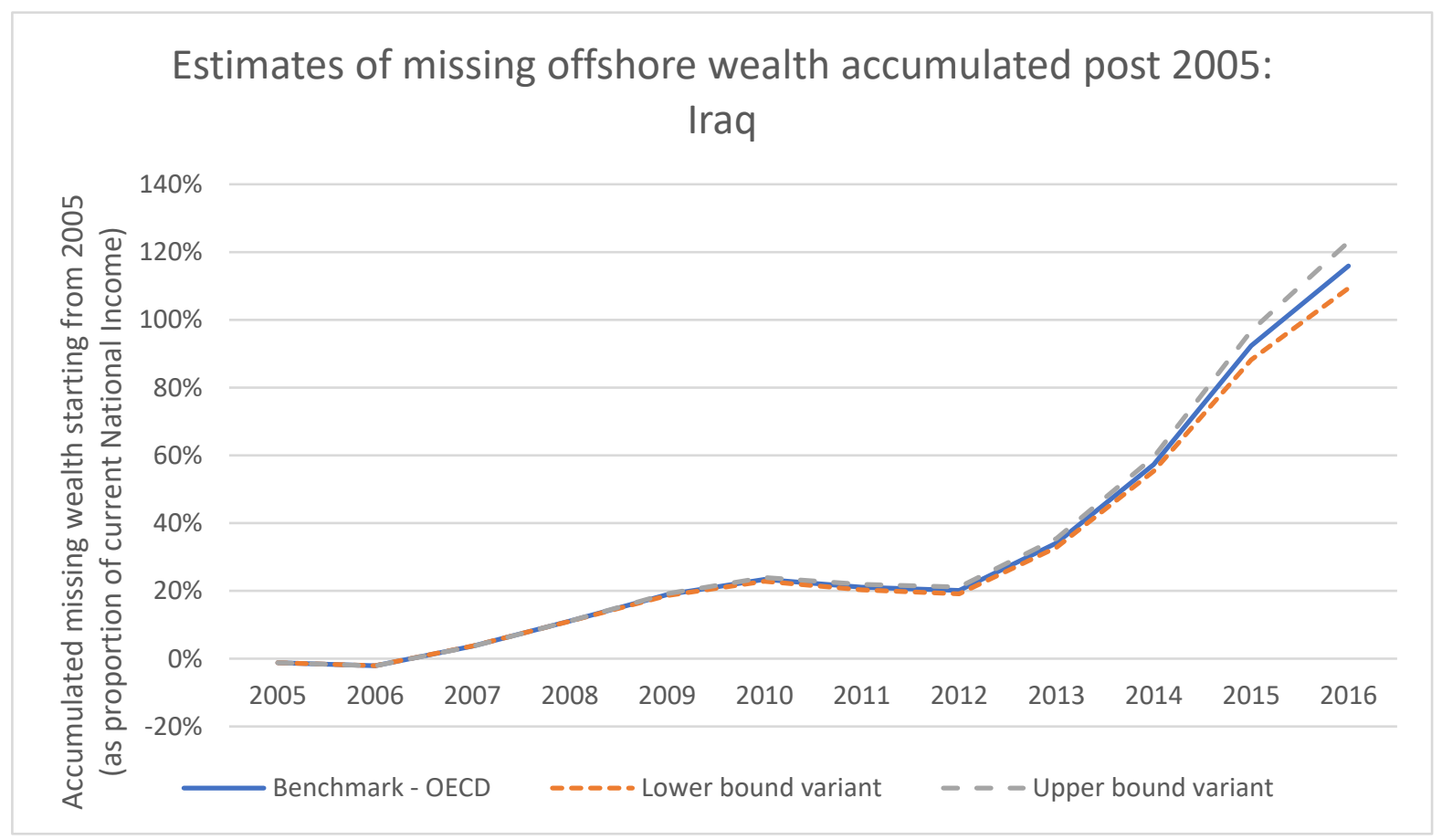

Figure 10. Missing wealth accumulated from 2005: Lower and Upper bounds

Therefore, in the case of Iraq, we only provide estimates of accumulated hidden foreign wealth starting from 2005 and not the total outstanding hidden offshore wealth; we call this a conservative estimate. As per our benchmark estimate derived from OECD growth rate, the Iraqi wealth hidden in offshore assets accumulates to $116 \%$ of national income in 2016; having lower and upper bound at $109 \%$ and $123 \%$ respectively (see Fig. 10). As evident from Fig. 11, 
if the benchmark rate of return on offshore wealth is taken as the world GDP growth rate or Iraqi GDP growth rate, then the estimate of accumulated hidden offshore wealth between 2005 and 2016 comes out to be larger (119\% or $136 \%$ respectively) than the OECD case (116\%). The magnitude of these numbers is simply astonishing given the fact that these do not contain hidden wealth amassed before 2005.

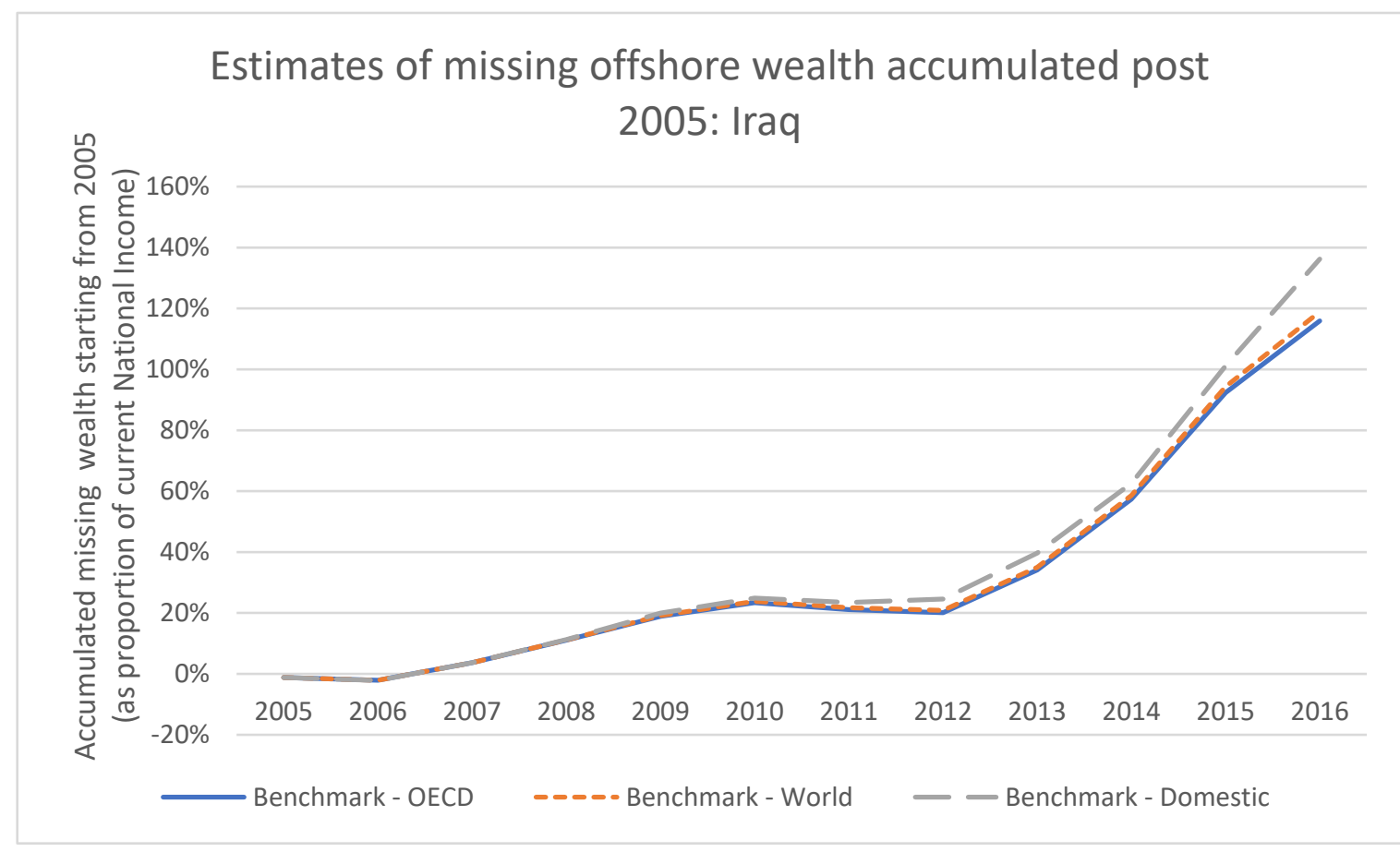

Figure 11. Missing wealth accumulated from 2005: varying growth rates

\subsection{Nigeria}

Nigeria is the largest oil producer in Africa. However, it has witnessed a consistent decline in its current account surplus over the last decade, which has fallen from $48 \%$ of national income in 2005 to just 1\% in 2016, and even recorded a negative current account balance in 2015 . Even under these times of falling export revenues, the cumulated amount of Nigeria's current account surplus from 2005 to 2017 (\$200 bn) is almost two times larger than the increase recorded in Nigeria's official foreign wealth over the same period ( $\$ 110$ bn). This inconsistency indicates towards a cumulated illicit capital flight of around $\$ 90$ bn in this twelve-year period.

At the time of writing, BoP data for Nigeria is available from 1977 to 2017 whereas the data for net foreign investment position is available only for the period of 2005 to 2016 . As evident from Fig. 12, net errors and omissions reported in Nigerian BoP statistics fluctuated around 
zero from 1977 to 2004, then became consistently negative (sign reversed in Fig. 12) from 2005 to 2014. This implies that net errors and omissions do not serve as a reliable estimator of illicit capital flight for the period 1977-2004 and we certainly can't assign zero value to outstanding hidden foreign wealth in 2004.

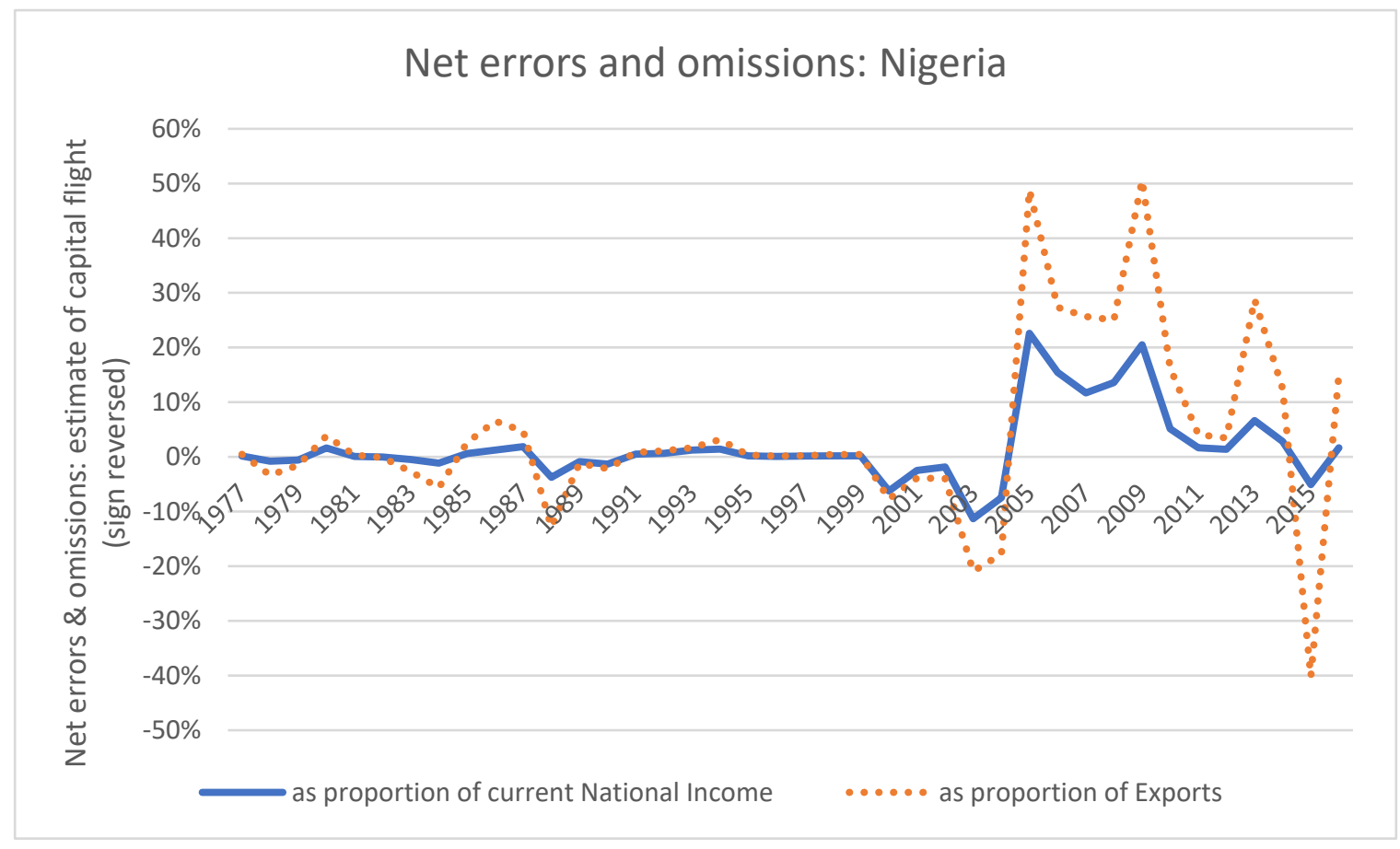

Figure 12. Net Errors and Omissions in BoP: Nigeria

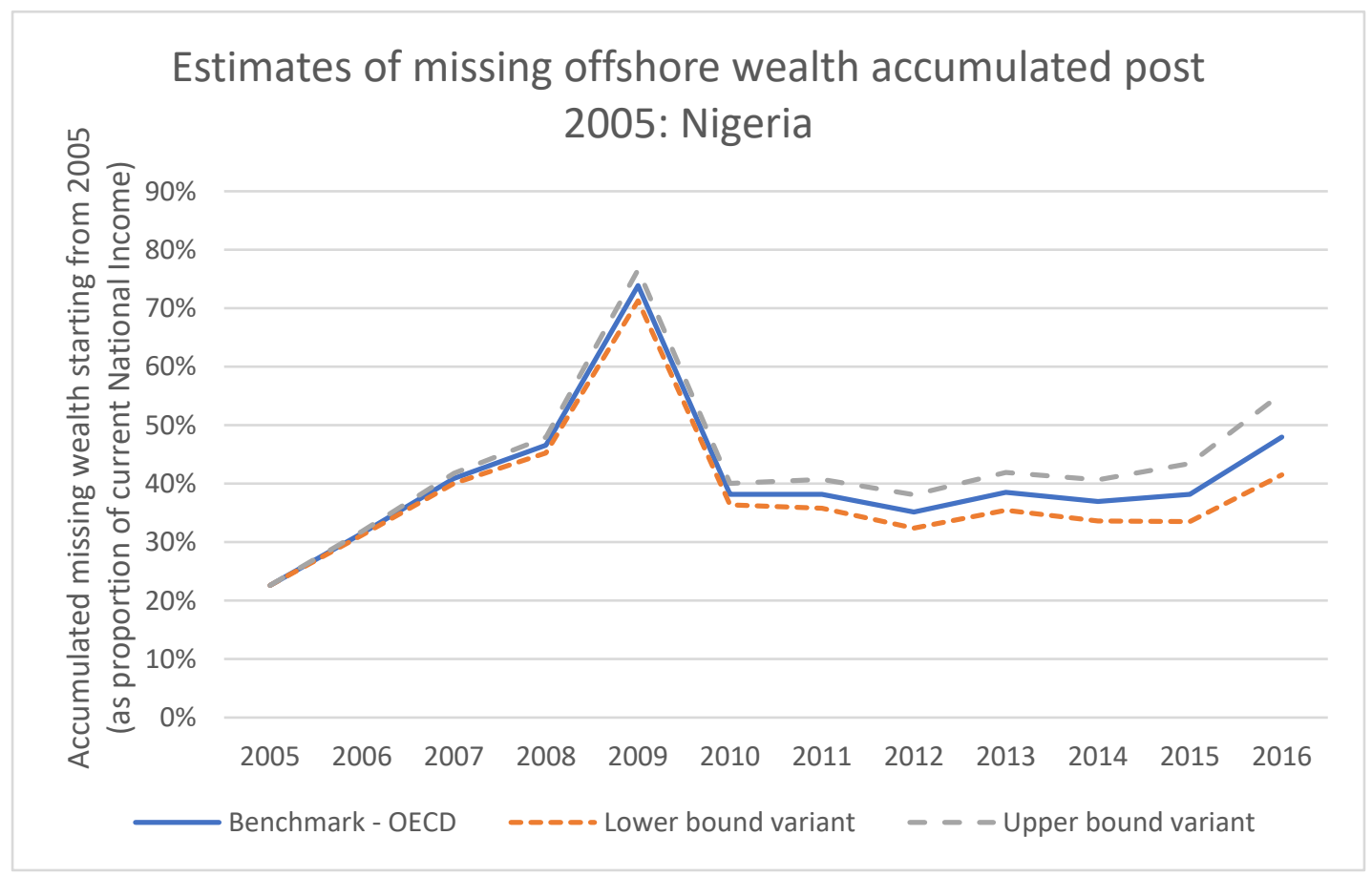

Figure 13. Missing wealth accumulated from 2005: Lower and Upper bounds 
As a result, we are only able to provide estimates of accumulated hidden foreign wealth starting from 2005 and not the total outstanding hidden offshore wealth; we call this conservative estimate. As per our benchmark estimate derived from OECD growth rate, the Nigerian wealth hidden in offshore assets accumulates to $48 \%$ of national income in 2016; having lower and upper bound at $42 \%$ and $45 \%$ respectively (see Fig. 13). As evident from Fig. 14 , if the benchmark rate of return on offshore wealth is taken as the world GDP growth rate or domestic GDP growth rate, then the estimate of accumulated hidden offshore wealth between 2005 and 2016 comes out to be larger (52\% or 62\% respectively) than the OECD case (48\%). The total wealth accumulated in hidden offshore assets between 2005 and 2017 is more than $\$ 170$ bn as per our OECD benchmark estimate.

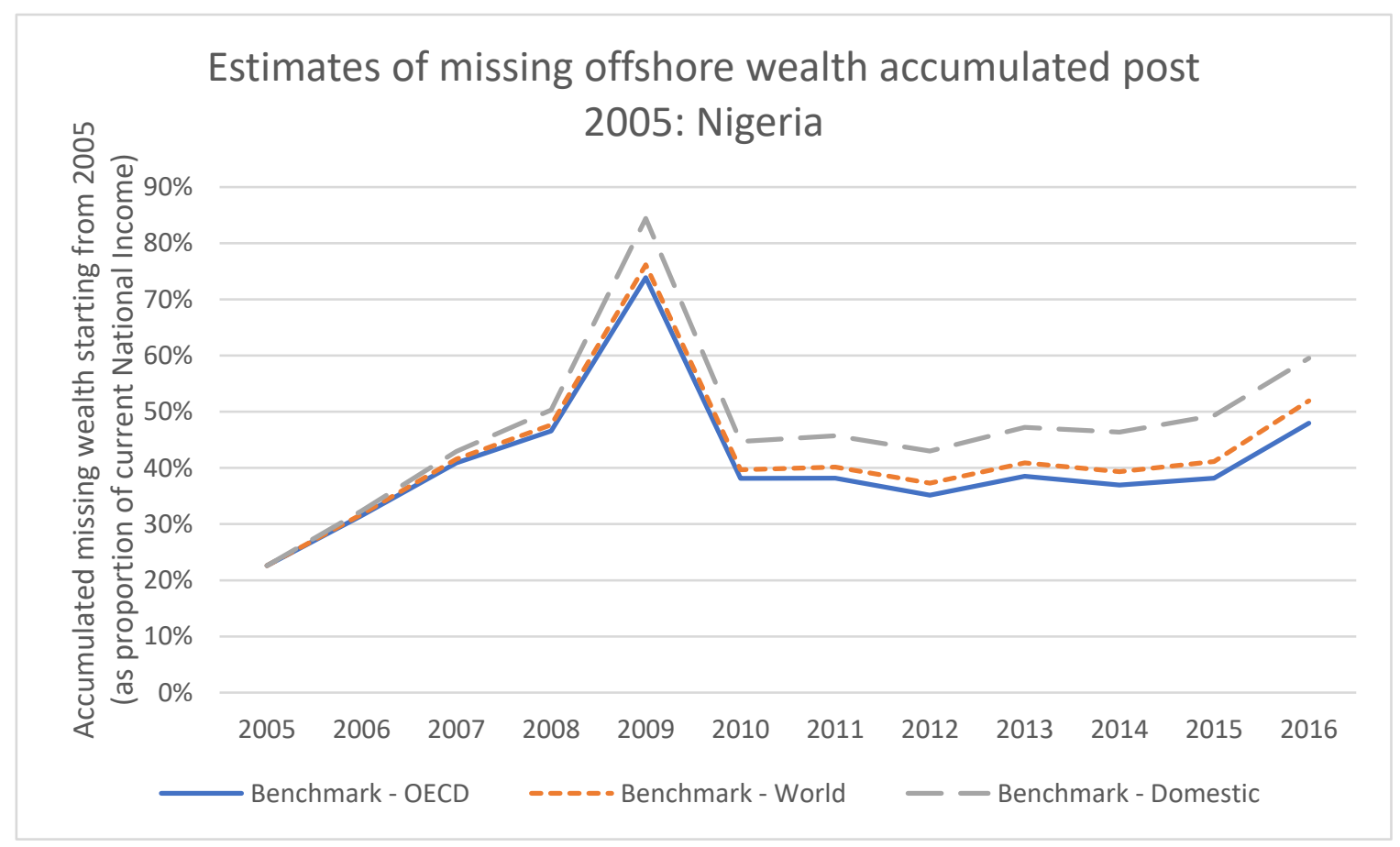

Figure 14. Missing wealth accumulated from 2005: varying growth rates

\section{Conclusion}

By definition, "hidden" offshore assets are notorious to estimate, and we certainly do not claim that the benchmark estimates calculated in this article are perfectly precise. But the orders of magnitude appear realistic, and if anything the reported results may be somewhat under-estimated. It is interesting to ponder upon the nature and status of holders of this hidden offshore wealth: first, there are ex-residents who are now foreign residents, and who 
were able to move their wealth via unreported offshore transactions. Next category is of residents who still are the citizens of the country under study but are able to accumulate foreign wealth through unreported offshore transactions. Lastly, one can't deny the possibility of these unreported funds being used for terror financing and other criminal activities - a scenario in which this unrecorded outflow of money is not being accumulated as wealth but is rather being consumed in sponsoring violent activities ${ }^{5}$. The estimates of offshore wealth presented in this article can be interpreted as the sum of the above three components and here we have not attempted to provide a formal breakup among these components.

The nature of the destination of these unrecorded outflows is even more uncertain: some of the funds might be getting invested back in domestic corporations as round-tripping, some might be getting invested abroad (e.g., a mansion in high-end real estate markets of London, Miami, Doha, Dubai or Sydney, or a company in Germany, Italy or elsewhere) or some of the drained money might just be getting consumed in financing terror networks; unscrambling this is going to be very tough. In this preliminary study, we have not attempted to disentangle the illicit capital flight taking place through various channels of outflow; but with richer data this could certainly be done, for instance, estimates of misinvoicing can be made by leveraging IMF's Direction of Trade database and looking at discrepancies in the domestic trade data and trading partner data.

The political and macroeconomic implications of money laundering are severe, both for the domestic and global economy (Quirk, 1997). Governments, succumbing to unscrupulous financial institutions, often cite that anti-money laundering measures, as proposed by Financial Action Task Force (FATF) - the money laundering watchdog, run contrary to the IMF's recommendation of loosening foreign exchange controls and financial liberalization. It is essential to rebut this argument and educate the public that laying measures for controlling money laundering is not the same as enforcing capital exchange controls. Money laundering vigilance requires information on, rather than control of, outflows and inflows of money. The type of information required for monitoring money laundering is different from that required

\footnotetext{
${ }^{5}$ As per a secret December 2009 US embassy cable signed by the US Secretary of State which was leaked to the newspaper, The Guardian, by whistle-blowers' website WikiLeaks (2013), "...Saudi Arabia remains a critical financial support base for al-Qaida, the Taliban, LeT and other terrorist groups"
} 
for capital exchange controls. Countries that exercise exchange controls require information on the economic motive of transactions, for enforcement purposes. Authorities monitoring money laundering, on the other hand, are more interested in KYC (know your customer) data for establishing the identities of transactors and the patterns of their transactions. A new conduit for money laundering is emerging - cryptocurrencies such as Bitcoin, transactions in which are virtually anonymous, and to regulate this new threat FATF must come out with appropriate guidelines and international standards for crypto exchanges and other financial institutions dealing in cryptocurrencies.

\section{References}

1. Center For Advanced Defense (C4ADS). (2018). Sandcastles: Tracing sanctions evasion through Dubai's luxury real estate market. Washington, D.C.: Center For Advanced Defense

2. European Commission, International Monetary Fund, Organisation for Economic Co-operation and Development, United Nations, and World Bank. (2009). System of national accounts 2008.

3. International Monetary Fund (IMF). (2013). Balance of payments and international investment position manual. $6^{\text {th }}$ ed. Washington, D.C.: International Monetary Fund

4. Lange, G. M., Wodon, Q., \& Carey, K. (Eds.). (2018). The changing wealth of nations 2018: Building a sustainable future. The World Bank.

5. Messner, J.J. (2018). 2018 Fragile States Index. USA: Washington, D.C.: Fund for Peace

6. Novokmet, F., Piketty, T., \& Zucman, G. (2018). From Soviets to oligarchs: inequality and property in Russia 1905-2016. The Journal of Economic Inequality, 16(2), 189-223.

7. Pietschmann, T., \& Walker, J. (2011). Estimating illicit financial flows resulting from drug trafficking and other transnational organized crimes. UNODC, United Nations Office of Drugs and Crime.

8. PricewaterhouseCoopers (PwC). (2016). Global Economic Crime Survey 2016: Adjusting the Lens on Economic Crime. PwC United States

9. Quirk, P. (1996). IMF Working Paper: Macroeconomic Implications of Money Laundering. USA: INTERNATIONAL MONETARY FUND. doi: https://doi.org/10.5089/9781451962123.001

10. Quirk, P. J. (1997). Money laundering: muddying the macroeconomy. Finance and Development, $34(1), 7$.

11. WikiLeaks. (2013). US embassy cables: the documents. Secret US embassy cables taken from a cache of 250,000 cables leaked to the Guardian by whistleblowers' website WikiLeaks. The Guardian. https://www.theguardian.com/world/us-embassy-cables-documents/242073. Accessed on Nov 14, 2018. 